\title{
ROLE OF D-DIMER IN DIAGNOSIS OF ACUTE CEREBRAL VENOUS THROMBOSIS
}

\author{
By \\ ${ }^{1}$ Nabil Hussein Mohamed, ${ }^{1}$ Abd El-Monem Mohamed Hassan, ${ }^{2}$ Abd El- \\ Aleem Ali El-Gendy and ${ }^{1}$ Ahmed Shawky Mahmoud \\ ${ }^{1}$ Department of Neurology, Faculty of Medicine, Al-Azhar University \\ ${ }^{2}$ Department of Clinical Pathology, Faculty of Medicine, Al-Azhar University \\ Corresponding Author: Ahmed Shawky Mahmoud, E-mail: algophilia91@gmail.com
}

\begin{abstract}
Background: Cerebral venous thrombosis (CVT) is a long-term debilitating vascular brain disease with high morbidity and mortality. Plasma levels of D-dimer are shown to be elevated and sensitive for the diagnosis of cerebral venous thrombosis (CVT).

Objective: To evaluate the usefulness of plasma D-dimer levels in diagnosis of cerebral venous thrombosis.

Patients and methods: This case-control study was conducted on two groups, patient group (40 patients) with CVT, and control group (10 patients) without CVT. All patients were subjected to full history and complete general and neurological examination focusing on headache either isolated or with symptoms of increased intracranial pressure (nausea/vomiting, papilledema, visual disturbance, disturbance of consciousness), focal motor deficit, cranial nerve palsy, or seizure. Fundus examination was done to detect papilledema and brain MRI and MRV to detect CVT, and determine the affected sinus. D-dimer levels were measured by the rapid sensitive D-dimer assay. The study was done at Department of Neurology, Al-Hussein and Sayed Galal University Hospitals, Cairo, Egypt.
\end{abstract}

Results: Among patient group, 30 (75\%) patients were females, while 10 (25\%) patients were males, and the mean of age was 27.4 years. The common presenting symptom was headache with blurred vision in 21 $(52.5 \%)$ patients, followed by focal seizures in $10(25 \%)$ patients. The most common sinus involved was right (Rt.) transverse sinus in $14(35 \%)$ patients. Twenty-seven $(67.5 \%)$ patients had papilledema. D-dimer test was positive in $39(97.5 \%)$ patients in patient group, while in the control group 1 patient $(10 \%)$ was positive and 9 patients (90\%) were negative.

Conclusion: Raised D-dimer level was often helpful for early diagnosis of CVT and an important screening tool to determine the early need of neuroimaging in patients who were suspected to have CVT. Negative Ddimer test did not exclude CVT, but indicated that acute CVT was very unlikely.

Key Words: D-dimer, Cerebral Venous thrombosis, Magnetic resonance venography (MRV).

\section{INTRODUCTION}

Cerebral venous and dural sinus thrombosis are an uncommon cause of stroke and is often more difficult to diagnose than usual causes of stroke (Ramrakhiani et al., 2019). Presentation can also be with non-stroke syndromes and overall CVT has an incidence of 0.22-1.32/100,000/year (Behrouzi and Punter, 2018). The most common clinical manifestations are headache, seizures, altered consciousness, and neurological focal signs on physical examination. CVT can manifest as a single symptom, or it can present as a syndrome consisting of multiple symptoms. This non-specific 
clinical picture makes diagnosing CVT difficult (Luo et al., 2018).

The gold standard for the diagnosis of CVT is magnetic resonance venography (MRV). A computed tomography (CT) scan has limitations, as it is positive only in 70\% of the cases (Misra et al., 2009). However, the difficulties associated with the use of these techniques have hindered their application as general screening methods for CVT (Hashami et al., 2016). Plasma levels of D-dimer, a biological marker of endogenous fibrinolysis, shown to be elevated and sensitive for the diagnosis of deep vein thrombosis including cerebral venous thrombosis. A number of studies have confirmed the usefulness of D-dimer level in venous sinus thrombosis (Al-Hashel et al., 2015).

The aim of the current study to evaluate the usefulness of plasma D-dimer levels in diagnosis of cerebral venous thrombosis.

\section{PATIENTS AND METHODS}

This prospective case-control study was carried out at Al-Hussein and Sayed Galal University Hospitals. This study was approved by the local Ethics Committee, Faculty of Medicine, AlAzhar University. Patients were consecutively enrolled from June 1st, 2019 to November 30th 2019 after obtaining signed informed consents. All patients were presented with suspected CVT. The patients were stratified according to results of neuroimaging study into two groups:

1. Patient group: Forty patients confirmed as CVT by MRV.
2. Control group: Ten patients free of CVT by MRV.

\section{Inclusion criteria:}

1. Patients diagnosed as CVT clinically and radiologically.

2. Symptom onset within 7 days.

\section{Exclusion criteria:}

1. Previous event of other hypercoagulable states such as deep venous thrombosis (DVT) and disseminated intravascular coagulation (DIC) or consequent events such as pulmonary embolism.

2. Other conditions associated with elevated serum level of D-dimer such as pregnancy, liver disease, kidney disease, cancer, rheumatoid arthritis, septicemia, meningitis, and thrombolytic therapy.

3. Atrial fibrillation demonstrated by ECG.

4. Confounding factors such as brain trauma or other brain damage with a clear etiology were excluded after undergoing emergent brain CT.

5. Symptom onset more than 7 days.

6. Patients rejected enrollment in the study or patients who died within 24 hours from arrival to hospital.

All patients were subjected to the following:

1. Full history and complete general and neurological examination focusing on; headache either isolated or with symptoms of increased intracranial pressure (nausea/vomiting, papilledema, visual disturbance, disturbance of consciousness), focal 


\section{ROLE OF D-DIMER IN DIAGNOSIS OF ACUTE CEREBRAL VENOUS...}

motor deficit, cranial nerve palsy, or seizure.

2. Fundus examination to detect papilledema.

3. Laboratory investigations in the form of:

i. $\mathrm{CBC}$, liver functions, kidney functions and rheumatoid factor to exclude other causes of elevated Ddimer.

ii. Quantitative D-dimer in venous sample was withdrawn in citrated tube to be measured within a period of time not exceeding 3 hours using ELISA DDimer kits.

4. Brain MRI and MRV using $1.5 \mathrm{~T}$ superconducting magnetic system Philips Achieva, and the whole brain was scanned with a slice thickness of 5 $\mathrm{mm}$ and a $1.5 \mathrm{~mm}$ inter-slice gap producing 19 axial imaging. The imaging protocol consisted of:

i. T2 weighted gradient echo.

ii. T1 weighted spin echo.

iii. Fluid-attenuated inversion recovery (FLAIR).

iv. Diffusion-weighted echo.

v. Magnetic resonant venography.

\section{Statistical analysis:}

Data were analyzed using a Statistical Package for Social Science (SPSS) version 18.0. Quantitative data were expressed as mean \pm standard deviation. Qualitative data were expressed as frequency and percentage No (\%). Chisquare test: was used when comparing non-parametric data. P-values were considered statistically significant at $\mathrm{P}<$ 0.05 .

\section{RESULTS}

The mean age in patients group was $27.4 \pm 9.9$ years, $30(75 \%)$ of them were females while the other $10(25 \%)$ were males (Table 1). Headache with blurred vision was the most common presenting symptom in $24(60 \%)$ patients, focal seizures in $8(20 \%)$ patients, hemi-paresis in $5(12.5 \%)$ patients, and GTC seizures in 3 (7.5\%) patients (Fig.1). Twenty-seven (67.5\%) patients had papilledema. MR venography revealed the involvement of transverse sinus in $25(67.5 \%)$ patients, superior sagittal sinus (SSS) in $8(20 \%)$ patients, and deep venous system in 7 (17.5\%) patients (Fig.2).

All patients had normal values as regarding ALT, AST and serum creatinine (Table 1).
In the control group, the mean age was $30.6 \pm 7.7$ years, $7(70 \%)$ of them were females. Headache with blurred vision were the presenting symptom in $5(50 \%)$ patients, tension headache in $3(30 \%)$ patients, and migraine in two (20\%) patients. Five $(50 \%)$ patients had papilledema. All patients had normal values as regard ALT, AST and serum creatinine (Table 1).

There was no statistically significant difference between studied groups as regard age, sex, liver enzymes, renal functions and interval between onset and sample withdrawal.

There was highly statistically significant difference between studied groups as regard plasma D-Dimer level. Plasma D-Dimer levels were elevated 
(positive D-Dimer test results) in 39 $(97.5 \%)$ patients of patient group, while there was $1(10 \%)$ patient with positive test results, and $9(90 \%)$ patients. negative (normal plasma D-Dimer level) in control group (Table 2).

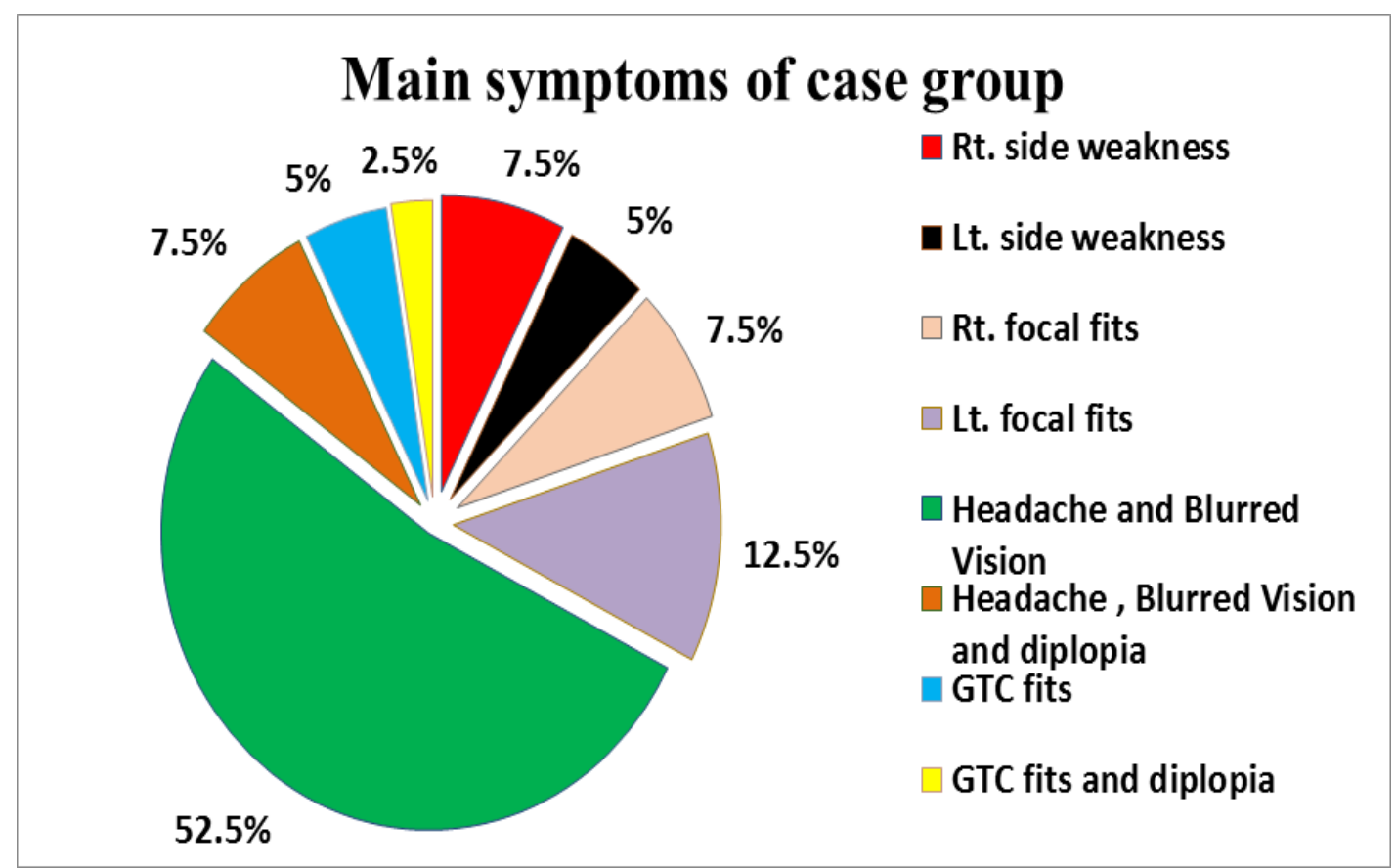

Figure (1): Description of main symptoms in case group

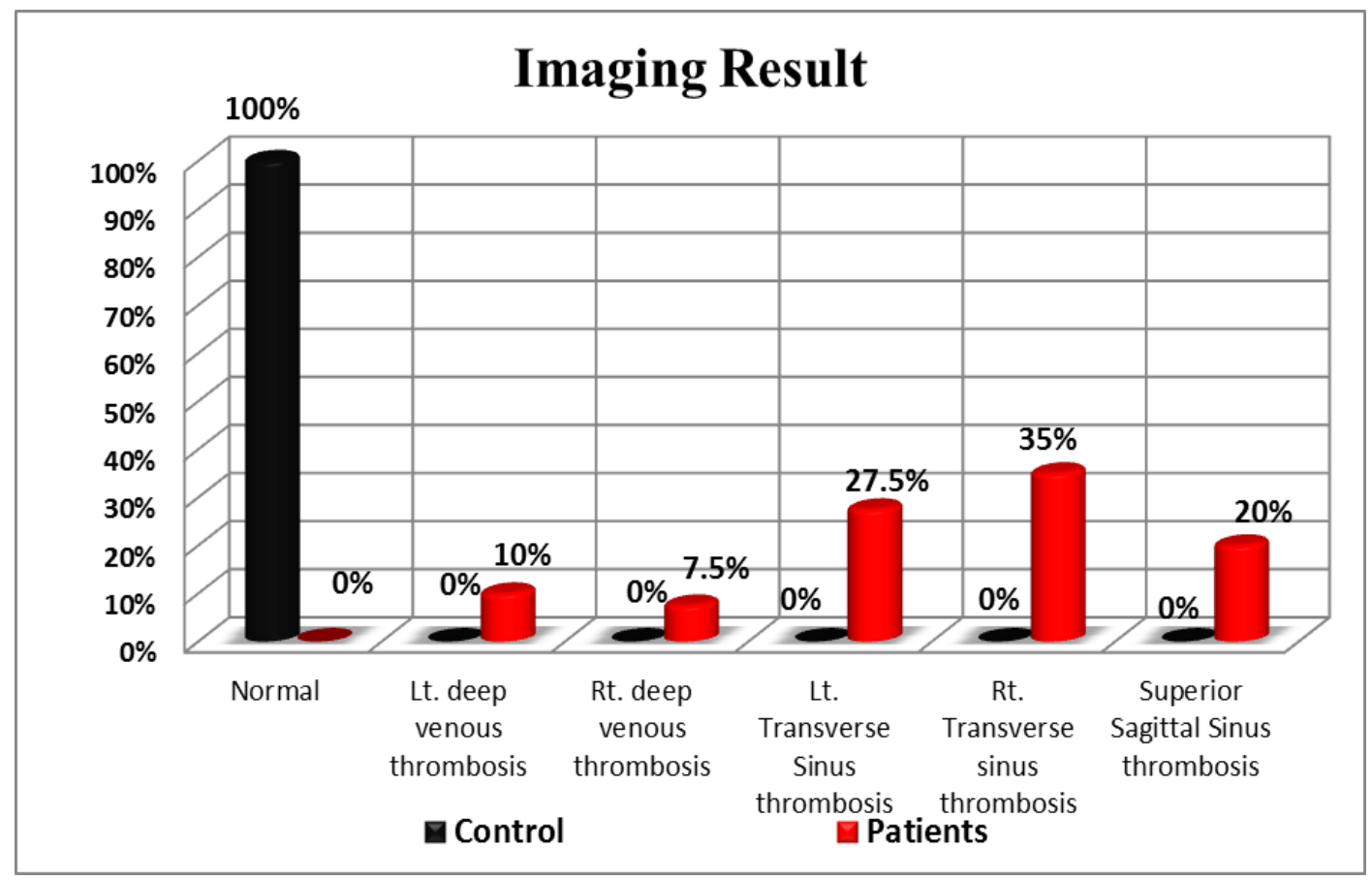

Figure (2): Description of neuroimaging study in control vs patient groups 
Table (1): Demographic Data of the studied groups

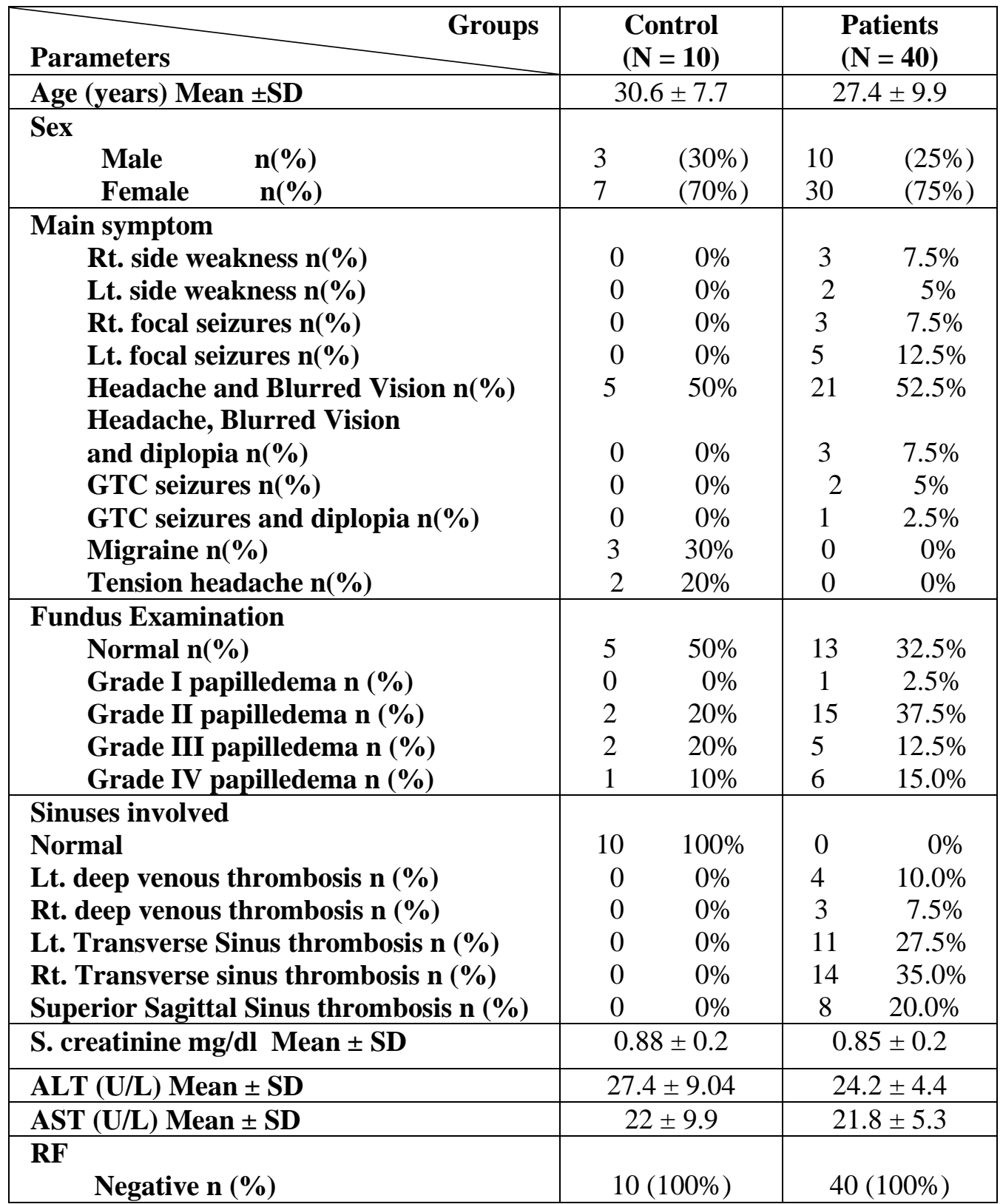

Table (2): Comparison between studied groups as regard D-dimer test

\begin{tabular}{|c|c|c|c|c|}
\hline \multicolumn{2}{|c|}{ Groups } & $\begin{array}{c}\text { Control } \\
(\mathrm{N}=5)\end{array}$ & $\begin{array}{c}\text { Patients } \\
(\mathrm{N}=40)\end{array}$ & P-value \\
\hline Darameters & Mean \pm SD & $0.22 \pm 0.3$ & $2.6 \pm 0.9$ & $<0.001$ \\
\hline
\end{tabular}




\section{DISCUSSION}

In the current study, the mean age in patient group was $27.4 \pm 9.9$ years.

Cerebral venous thrombosis was found to be more common in females as compared with males. Thirty (75\%) patients in the patient group were females. This was in agreement with Vijay and Ajay (2017) study.

Several factors explain the prevalence of sinus thrombosis in middle-aged females compared to old ages and males such as pregnancy, puerperium, effect of sex hormones and the use of oral contraceptive pills which all account for increased blood coagulability. Hence middle-aged females are affected more commonly as compared with old ages and males, respectively (Ferro et al., 2016).

In the current study, headache was the most common presenting symptom seen in $60 \%$ of patients followed by seizures in $27.5 \%$ of patients. This was in agreement with Misra et al. (2009) study.

The current study showed that $67.5 \%$ of patients had papilledema. These results were in agreement with Akila et al. (2017) study.

The current study showed that the most involved sinuses were transverse sinus in $67.5 \%$ of patients followed by superior sagittal sinus (SSS) in $20 \%$ of patients. This was in agreement with the studies of Al-Hashel et al. (2015) and Hashami et al. (2016).

Being horizontal unlike most of other cerebral venous sinuses which are perpendicular directing their blood content towards internal jagular veins, transverse sinuses seem to have a slower velocity of blood flow after passing through the confluent of sinuses which is considered a point of heavy traffic for blood flow (Maheshwari et al., 2017).

The current study findings demonstrated that plasma D-Dimer level in the CVT group was significantly higher than the non-CVT group being elevated (positive D-Dimer test results) in $97.5 \%$ out of patient group compared to control group in which only $10 \%$ had positive DDimer test results.

The results of current study were supported by the studies of Meng et al., (2014), Hashami et al. (2016), Akila et al. (2017) and Vijay and Ajay (2017).

On the other hand, results obtained in this study were in disagreement with $\mathrm{Al}$ Hashel et al. (2015) which can be explained by the fact that in this study, there was a long duration between disease onset and sample collection which ranged from 3 days to 4 weeks in most of patients included compared to the current study in which the duration between disease onset and sample collection ranged from 1 to 7 days.

\section{CONCLUSION}

Raised D-dimer level is useful for early diagnosis of CVT and an important screening tool to determine the early need of neuroimaging in patients who are suspected of CVT. However, suspected patients with normal plasma D-Dimer level should not be excluded from the diagnoses of CVT.

\section{CONFLICT OF INTEREST}

The authors have no conflict of interest related to this publication. 


\section{REFERENCES}

1. Akila A, Ananthi $M$ and Manojkumar $V$ (2017): Evaluation of Plasma D-Dimer as an Initial Diagnostic Biomarker in Cerebral Venous Thrombosis- A Prospective Cross Sectional Study. IOSR Journal of Dental and Medical Sciences, 16(5): 41-46.

2. Al-Hashel JY, Ahmed SF, Youssry D, Alroughani RA, Ismail II and Vemba P (2015): The value of D-Dimer test for diagnosis of Cerebral venous thrombosis in Kuwait Neurological Center. Emergency Medicine, 5(4): 1-3.

3. Behrouzi AR and Punter M (2018): Diagnosis and management of Cerebral venous thrombosis. Clinical Medicine, 18(1): 75-79.

4. Ferro JM, Canhão $P$ and Aguiar de Sousa D. (2016): Cerebral venous thrombosis. Presse Med, 45: 429-435.

5. Hashami L, Rakhshan V, Karimian $H$ and Moghaddasi M (2016): Diagnostic value of D-dimer's serum level in Iranian patients with cerebral venous thrombosis. Neurology International, 8: 63-102.

6. Luo $Y$, Tian $X$ and Wang $X$ (2018): Diagnosis and treatment of venous thrombosis: A review. advances in Cerebral Venous Thrombosis Research, 10(2): 1-15.
7. Maheshwari D, Vijay S, Parag M, Bharat B, Sanklap M, Sumit $K$ and Piyush $O$ (2017): Role of D-Dimer in aseptic cerebral venous sinus thrombosis. Indian Journal of Neurosciences, 3(1): 21-25.

8. Meng R, Wang X, Hussain M, Dornbos III D and Meng L (2014): Evaluation of plasma d-dimer plus fibrinogen in predicting acute CVST. Int J Stroke, 9: 166-173.

9. Misra UK, Kalita J and Bansal V (2009): D-dimer is useful in the diagnosis of cortical venous sinus thrombosis. Neurol India, 57: 50-54.

10. Ramrakhiani N, Sharma DK, Ramfal D, Gupta P, Sharma A and Sharma KK (2019): Clinical Profile, Risk Factors and Outcomes in Patients with Cerebral Venous Sinus Thrombosis: A Study from Western India. Journal of The Association of Physicians of India, 67: 49-53.

11. Vijay K N and Ajay K N (2017): Study of Cerebral venous thrombosis in Central India..JMSCR, 5 (2): 17746-52. 


\section{دور تحليل اختبار دي دايمر في تشخيص التخثر الوريدي المخي الحاد}

1نبيل حسين محمد، 1عبدالمنعم محمد حسن، 2عبدالعليم علي الجندي، 1أحمد شوقي محمود

1قسم طب المخ والأعصاب، كلية الطب، جامعة الأزهر

2قسم الباثولوجيا الإكلينيكية، كلية الطب، جامعة الأزهر

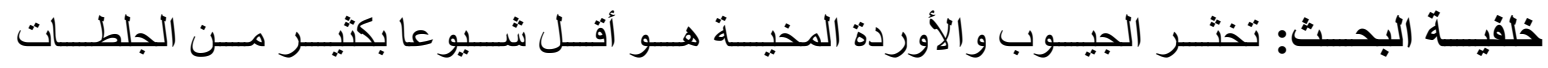

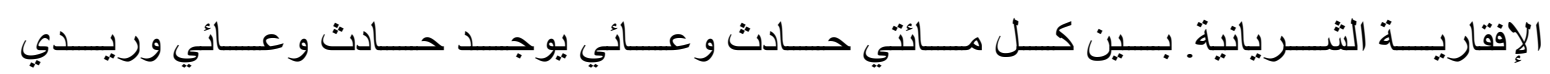

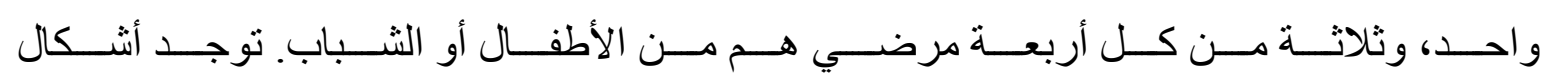

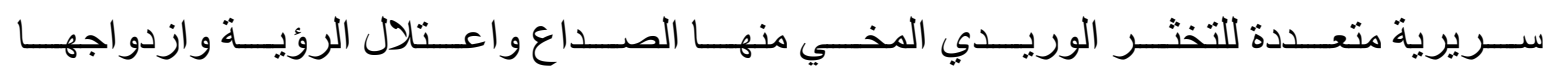

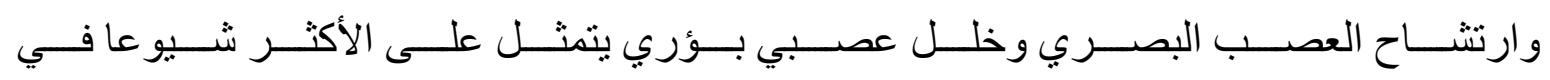

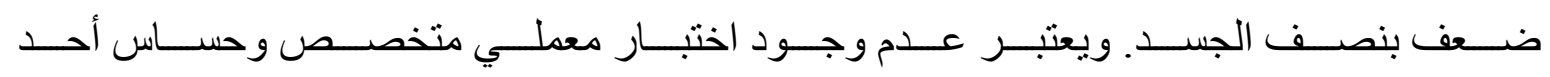

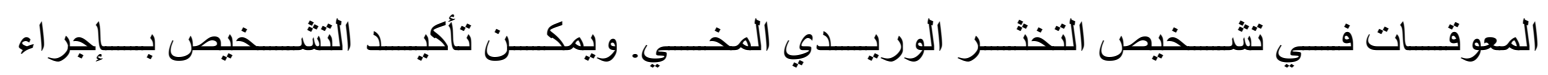

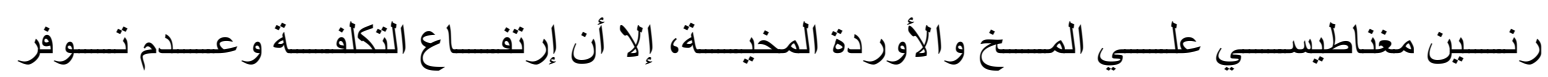

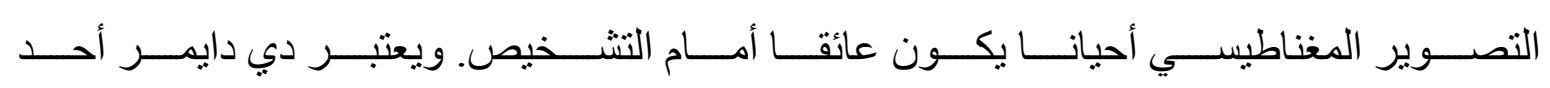

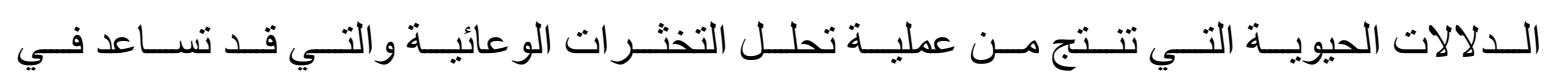
تشخيص التخثرات الوريدية المخية وزيادة احتمال وجودها.

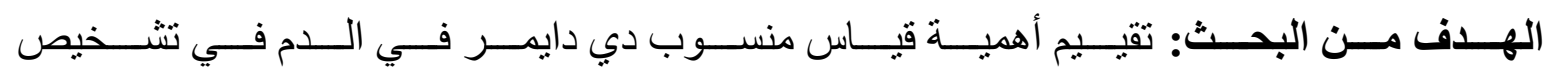
التخثر الوريدي المخي الحاد.

المرضي وطرق البحث: أجريت الدراسة الحالية على مجموعتين:

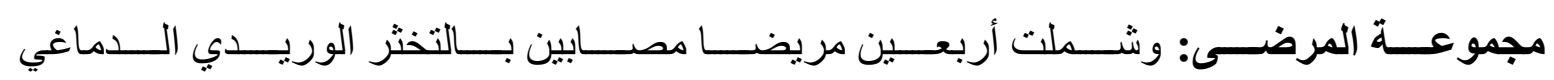

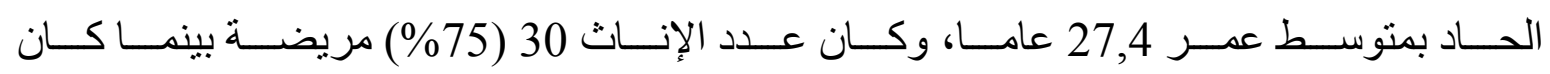

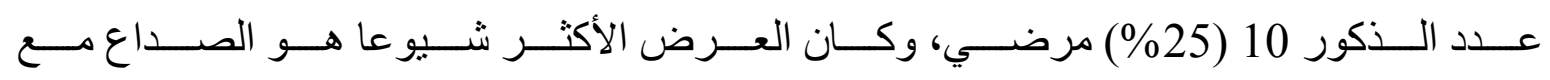

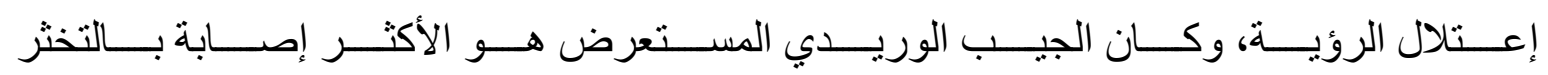

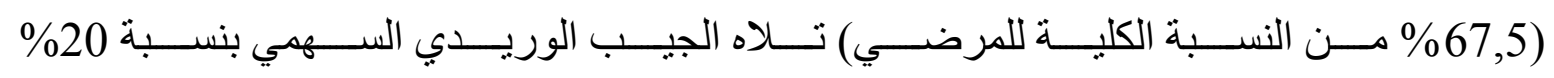
من النسبة الكلية للمرضي. 


\section{ROLE OF D-DIMER IN DIAGNOSIS OF ACUTE CEREBRAL VENOUS... 921}

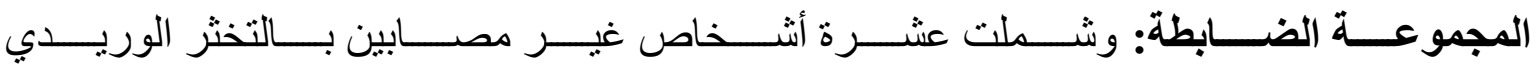

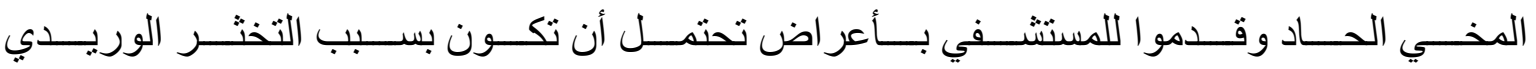
المخي إلا انه تم استبعاد التشخيص بعد عمل رنين مغناطيسي مخي لهم.

\section{نتائج البحث:}

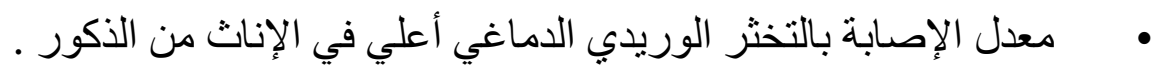
• متوسط عمر المصابين بالتخثر الوريدي الدماغي هو 27.4 عام.

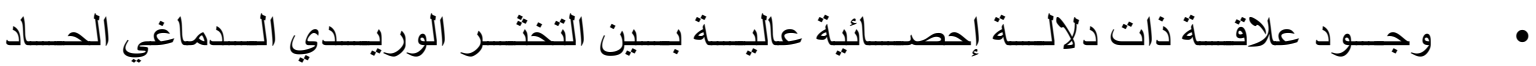
وبين مستوي تحليل دي دايمر.

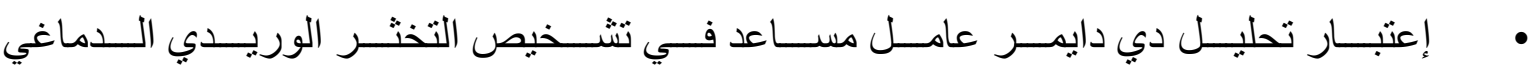
الحاد.

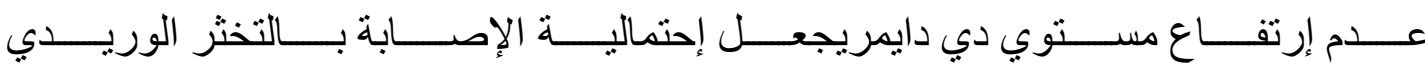
الدماغي مستبعدة.

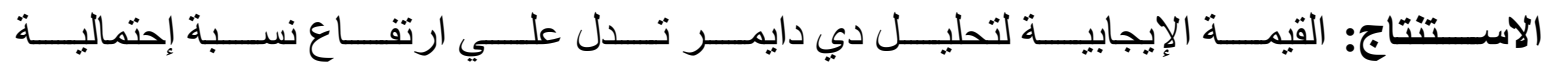

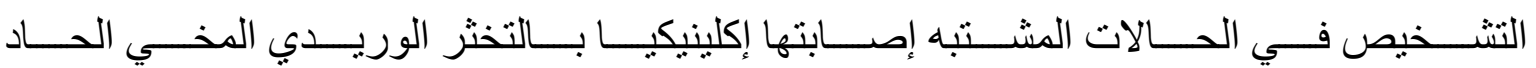

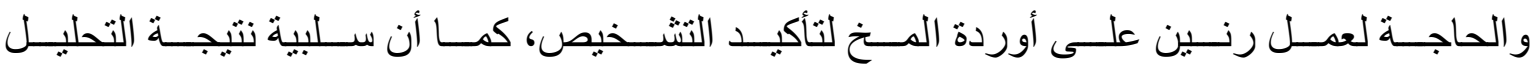
تدل على أن إحتمال الإصابة بالتخثر الوريدي المخي ضئيل للغاية. 